\title{
Ficus Exasperata Vah/ IMPROVES MANGANESE-INDUCED NEUROTOXICITY AND MOTOR DYSFUNCTION IN MICE
}

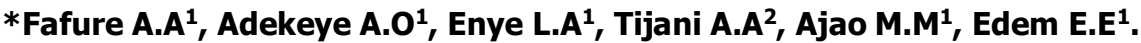 \\ ${ }^{1}$ Department of Anatomy, College of Medicine and Health Sciences, Afe Babalola University, Ado Ekiti, Nigeria \\ ${ }^{2}$ Department of Anatomy, College of Medicine, Ekiti State University, Ado Ekiti, Nigeria
}

Correspondence to FAFURE Adedamola Adediran, Department of Anatomy, Afe Babalola University, Ado Ekiti, Ekiti, Nigeria. Mobile: +2348069501996ロadedamolaf@abuad.edu.ng

\section{ABSTRACT}

Manganese is an important element in the biological system, however, excessive exposure may lead to a neurological disorder known as manganism. The present study sought to investigate the ameliorative effects of Ficus exasperata Vahl (E.Vahl) on motor function and neuronal integrity of the Substantia nigra (SNc) and Corpus striatum (CPu) after acute exposure to manganese. Fifty adult male Balb/c mice weighing between 25 - $35 \mathrm{~g}$ were divided into 5 groups - Group A (normal saline), Group B (Manganese), Group C (E.Vahl), Group D (Post-treatment), Group E (concurrent treatment). Manganese was intraperitoneally administered at $40 \mathrm{mg} / \mathrm{kg}$ b.w, while E.Vahl orally at $200 \mathrm{mg} / \mathrm{kg}$ b.w. Motor coordination was assessed in the animals using Rotarod and Parallel Bar tests. Animals were later sacrificed; brain tissue extracted and processed for histology/immunohistochemistry. Manganese-exposed group showed decreased motor activity on the Rotarod test. Decreased motor activity shown by the increase in latency of turn (LoF) was recorded in the Parallel Bar test. Manganese induced activation of microglia and astrocytic cells in the SNc and CPu, which plays an important role in neurodegeneration as observed in the reduction of TH cells. Indistinct Nissl granules were also noticed in the manganese-exposed group. Treatment with E.Vahl produced significant motor improvement, as well as ameliorative effect on the histoarchitecture of the SNc and CPu. The present investigation has demonstrated the motor-enhancing and neuro-restorative potential of E.Vahl after manganese exposure in adult mice.

Key Word: Neurodegeneration; Manganism; Ficus exasperata; Rotarod; immunohistochemistry.

\section{INTRODUCTION}

Medicinal herbs have played major roles in the treatment of various diseases and ailment in humans and animals (Mee-Young et al., 2013). However, their acceptability by some cultures of the world has been limited by lack of specific dose regimen and thorough scientific information on toxicity profile to validate their safety (Firenzuoli et al., 2007). However, due to the indiscriminate use of these plants, recent researches have been providing information on the safety of herbal preparations used in the management of diseases. One of the plants that have been scrutinized is Ficus exasperata Vahl (FEV) and it is known to contain active phytochemical compounds such as alkaloid, saponin, flavonoid and glycoside (Adebayo et al., 2009). Ficus exasperate vahl is a small tree that belongs to the family Moraceae and it is well known as a result of its rough leaves (Adebayo et al., 2009; Woode et al., 2011).
Foods and drinks are generally consumed for several purposes aimed at growth, development and maintenance of good health, but contamination of such food and drink with some metals such as lead, copper and manganese could cause potential hazard and neuronal toxicity (Jarup, 2003). Manganese (Mn) in humans can elicit a variety of serious toxic responses upon prolonged exposure to elevated concentrations either orally or by inhalation (Sax, 1984). It is essential for the proper function of several enzymes and is necessary for normal bone structure and brain function (U.S. EPA. 1994). Manganese (Mn) is an essential transition metal (Anderson et al., 2008; Erikson et al., 2007), but excessive exposure to manganese which is mainly through occupational inhalation, may eventually lead to central nervous system (CNS) toxic condition known as manganism. 
Despite its essentiality, excessive and prolonged inhalation of $\mathrm{Mn}$ particulates in mining, welding and industries results in its accumulation in selected brain regions that causes central nervous system (CNS) dysfunctions and an extrapyramidal motor disorder, referred to as manganism (Aschner et al., 2009; Dobson et al., 2004).

The primary brain targets of manganese are the basal ganglia (BG), a group of related subcortical nuclei that include the caudate nucleus and putamen which together formed the striatum; the globus pallidus which comprises an external and internal segment (GPe and $\mathrm{GPi}$, respectively) and the closely related subthalamic nucleus (STN) and substantia nigra (SNr) pars reticulata (SNr) and pars compacta (SNc) (Parent and Carpenter, 1996). These nuclei are components of circuits involving different areas of the cerebral cortex, thalamus and brainstem and are responsible for integrating and coordinating the information from various brain regions associated with motor and non-motor behaviors. In the brain, the striatum, globus pallidus (GP), SN, and STN have been reported as targets of manganese (Mn) with the GP as the primary site for its accumulation and neurotoxicity (Yamada et al., 1986; Aschner et al., 2007).

Many studies have tried to determine whether manganism occurs because of degeneration or dysfunction of dopaminergic neurons (Kornblith et al., 2017). There is recent evidence in the literature that rodents exposed to manganese $(\mathrm{Mn})$ also have impairment in dopamine release with no change in total tissue dopamine levels, dopamine neuron terminals in the striatum, or TH-positive dopaminergic cell bodies in the substantia nigra pas compacta (Vidal et al., 2005; Peneder et al., 2011). Studies have provided evidence that $\mathrm{Mn}$-induced Parkinsonism may be the result of the inability of dopamine neuron terminals to release dopamine rather than a decrease of dopamine synthesis in intact terminals and/or the loss of dopamine because of terminal degeneration (Kwakye et al., 2015).

\section{MATERIALS AND METHODS}

FEV leaves were collected in the month of May from a local farmland in Ikole-Ekiti, South-Western, Nigeria. The leaves were separated and dried under shade for five days and then pulverized into fine powder using an electric blender. A section of the fine powder was extracted in ethanol and the other in methanol for three days after which the extract was filtered. The filtrate was placed in a water bathe at a temperature of about $60^{\circ} \mathrm{C}$ for a period of between 24-48 hours to dry. The dried extract was reconstituted in normal saline to give a dose of $200 \mathrm{mg} / \mathrm{kg}$. Chemical tests were carried out using the methanolic mode of extraction to identify the plant active constituents in line with Liu et al., 2018.

Manganese (II) chloride $\left(\mathrm{Mncl}_{2} .4 \mathrm{H}_{2} \mathrm{O}\right)$ tetrahydrate, Sodium hydrogen Phospahte $\left(\mathrm{Na}_{2} \mathrm{HPO}_{4}\right)$, Potassium chloride $(\mathrm{KCL})$, Potassium dihydrogen phosphate $\left(\mathrm{KH}_{2} \mathrm{PO}_{4}\right)$ and all consumable used were purchased from Kermel laboratory (Colmar, France). The water used was glass-distilled and other reagents were of analytical grade.
Male adult BALB/c mice (8-10 weeks old) weighing 25-35 g were procured from animal handling facility of the Department of Anatomy, University of Ibadan, Oyo state, Nigeria. The animals were housed and fed in the animal holding of Afe Babalola University, Ado Ekiti. The mice were allowed to acclimatize for a period of two weeks and had free access to rodent chow (purchased from $A B U A D$ feed mill, Ado-Ekiti) and water and exposed to 12 hrs by 12 hrs dark and light period.

Mice were divided into 5 groups $(n=10)$. Group A received normal saline for three weeks, Group B was treated with manganese chloride $\left(\mathrm{MnCl}_{2}\right)$ for a week, Group C was treated with FEV extract for two weeks, Group D received manganese first with later treatment of FEV extract. Group $\mathrm{E}$ were treated with manganese and extract concurrently for two weeks. The manganese and FEV solution were freshly prepared and changed weekly. The manganese dose $(40 \mathrm{mg} / \mathrm{kg})$ and dosing route (intraperitoneal) used in this study for one week were modelled based on Jungmin, 2008, while the 
Ficus exasperate vahl dose $(200 \mathrm{mg} / \mathrm{kg})$ and dosing route (orally) for two weeks were also due to a model based on a report by Woode et al., 2011.

Behavioural assessments were carried out at the end of administration to assess the motor coordination of mice, using a rotarod and parallel bar test (Jungmin et al., 2008; Perona et al., 2008). Motor activity and coordination were measured in the animals using different battery of tests. These tests were carried out in a closed room with proper illumination and control in behavioural room. At the end of the treatments, all tests were done on mice using a digital video recorder and were analysed later for motor activity and coordination. The animals were familiarised with the behavioural apparatus before initiating the test. Both tests were performed in the animal holding behavioural designated room of Afe Babalola University, AdoEkiti, Nigeria.

Blood was collected in an anticoagulant (EDTA) tube using heart puncture and eye puncture where applicable, with a sterile syringe. After centrifugation at $1000 \times \mathrm{g}$ for $10 \mathrm{~min}$ at $4{ }^{\circ} \mathrm{C}$, the top yellow plasma layer was collected, white buffy layer (leukocytes) was discarded, and erythrocytes were collected (Seo et al., 2016). Samples were analysed for metals by inductively coupled plasma mass spectrometry (ICP-MS) in the Trace Metals Laboratory of Afe Babalola University, Ado-Ekiti, Nigeria.

The tissue samples were fixed in $10 \%$ formal saline, then dehydrated and embedded in paraffin wax and sectioned with rotary microtome at $8 \mu \mathrm{m}$. The embedded tissues sectioned were later floated out and stained with haematoxylin (Sigma MHS16)-eosin (Sigma HT110-1-32) solution to give a general overview of the tissues and Cresyl fast violet (CFV) stain to check for nissl substances in neurons. Immunohistochemistry was done using Glial fibrillary acidic protein (GFAP) to quantify astrocytic activities and its expression, CD11b/c to check for microglia activities and Tyrosine hydroxylase to quantify the Dopaminergic neurons. The tissues were then mounted and cover-slipped using Dako mounting medium. Photomicrographs were captured with Micro microscope with 5 mega pixel digital camera running a window program and mountage were assembled in Windows Paint.

Mice were sacrificed 48 hour after the last injection and neurobehavioural studies were done, based on previous studies that revealed a significant activation of astroglia (Vidal et al., 2005). Mice were sacrificed through cervical dislocation and transcardially perfused with paraformaldehyde (4\% in $0.1 \mathrm{M}$ phosphate buffer, $\mathrm{pH}$ 7.4). For immunohistochemistry studies, sections from the $\mathrm{CPu}$ and SNc (10 $\mu \mathrm{m}$ thick) were coronally cut on a microtome and immunoreacted with primary antibodies directed against GFAP, CD11b/c, and $\mathrm{TH}$. For diaminobenzidine (DAB) visualization of GFAP, the proper biotinilated secondary antibody (goat anti-mouse IgG for GFAP from Vector, United Kingdom) was used and the avidin-biotinperoxidase protocol (ABC, Vector, United Kingdom) was applied (Vidal et al., 2005). Sections were mounted on gelatin-coated slides, dehydrated and coverslipped.

Data were compared with Newman-keuls for post hoc. Relative brain weight and motor coordination performance of the treated group were compared with those of control using One-way analysis of variance (ANOVA). All results are presented as mean \pm SEM and are considered statistically significant at $p<0.05$.

\section{RESULTS}

After the last day of manganese exposure intraperitoneally, control mice showed improved locomotor skills by spending more time on the rotating bar. Ficus exasperate vahl shows significant increase in the retention time as they spent more time on the rotating bar compared to manganese treated group $(* * p<0.01)$. Motor activity of the Post treated group significantly decrease when compared to FEV group $\left(*^{*}<0.05\right)$. However, Concurrent treated group showed a significant decrease in the retention time on the rotating bar compared to E.vahl $(* * p<0.01)$. 
Significant increases in Latency of turn (LOT) scores were considered as abnormal motor coordination when the treatment groups were compared against control. Manganese exposed mice exhibited increased latency of turn (time to turn) and total time spent during the parallel bar test when compared to the control group. There was a significant decrease in the LOT of FEV and post treated group when compared with manganese treated group. However, Concurrent treatment group exhibited a decrease in time of turn compared to manganese treated group $(* \mathrm{p}<0.05, * * \mathrm{p}<0.01)$.

There was a statistically significant difference in the level of relative brain weight when the control group was compared with the treated groups. Manganese group showed a remarkable reduction when compared with the control group. Post

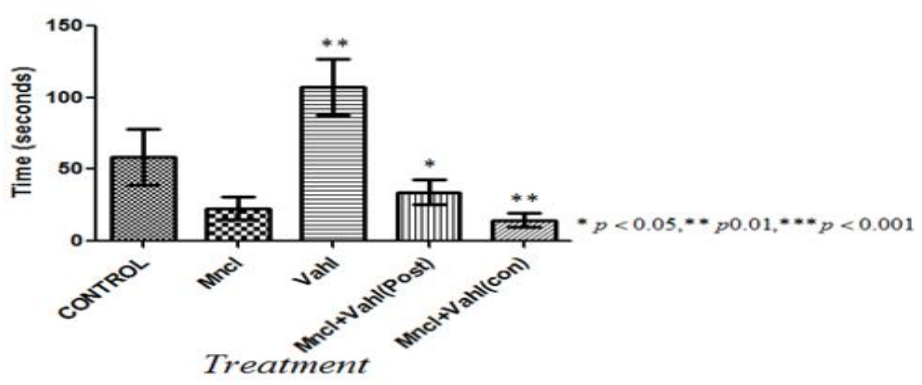

Figure 1: Graph showing the latency of fall of the experimental animals $(P$ value $=0.0014: F$ value $=7.728)$.

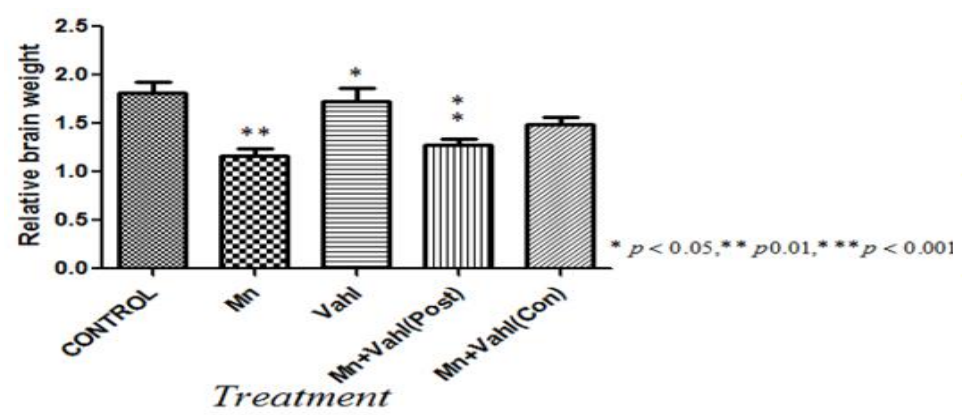

Figure 3: Bar chart showing the Relative Brain weight of the experimental animals $(P$ value $=0.0010$ : $F$ value=8.230). treatment group also shows reduction when compared to control and FEV. It can also be seen that the extract (FEV) revealed a statistically significant difference when compared with the Manganese treated group $\left({ }^{*} \mathrm{p}<0.05, * * \mathrm{p}<0.01\right)$.

Blood was collected in an anticoagulant (EDTA) tube using heart puncture and eye puncture where applicable with a sterile syringe. After centrifugation at $1000 \times \mathrm{g}$ for $10 \mathrm{~min}$ at $4{ }^{\circ} \mathrm{C}$, the top yellow plasma layer was collected, and analysed for metals by inductively coupled plasma mass spectrometry (ICP-MS). Mn exposures produced higher blood manganese levels than the control, Post and FEV group, but not significantly difference (Fig. 4). However, Concurrent treatment group shows a reduction in manganese level when compared to the manganese treated group.

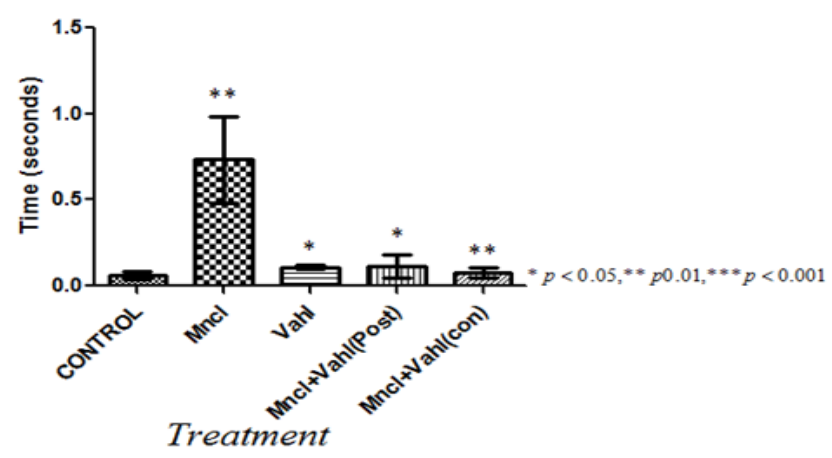

Figure 2: Graph showing the latency of turn of the experimental animals. ( $P$ value $=0.0040: \mathrm{F}$ value $=6.116$ ).

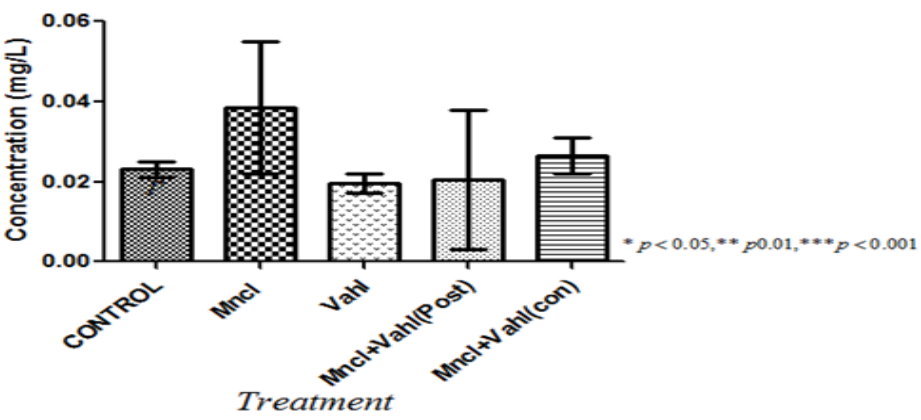

Figure 4: Bar chart showing the Mn Plasma Concentration ( $P$ value $=0.0128 ; \mathrm{F}$ value $=4.586$ ). 
Qualitative analysis of this plant following methanol and aqueous extraction shows that it contains: phenol, tannins, flavonoids, saponins, alkaloids, Steroids, and glycosides which have been identified by other researchers in various plants and in different parts of plants $[11,44,19,8$, and 1$]$ but the activities of alkaloids, Saponin and Glycosides were more pronounced with the methanolic extract. Quantitative analysis shows higher concentration of Saponin $(34.499 \mathrm{mg} / \mathrm{g}$, $34.489 \mathrm{mg} / \mathrm{g})$ and Alkaloids $(16.801 \mathrm{mg} / \mathrm{g}$,
$15.968 \mathrm{mg} / \mathrm{g}$ ) with Methanolic and Aqueous extract respectively.

Section of $\mathrm{TH}$ shows degeneration and scantily distribution of dopaminergic neurons in the manganese treated group when compared with the control. Concurrent treated demonstrates ameliorative roles when compared with the manganese. Post treated group shows recovery of the TH cells when compared to the manganese induce group of mice.
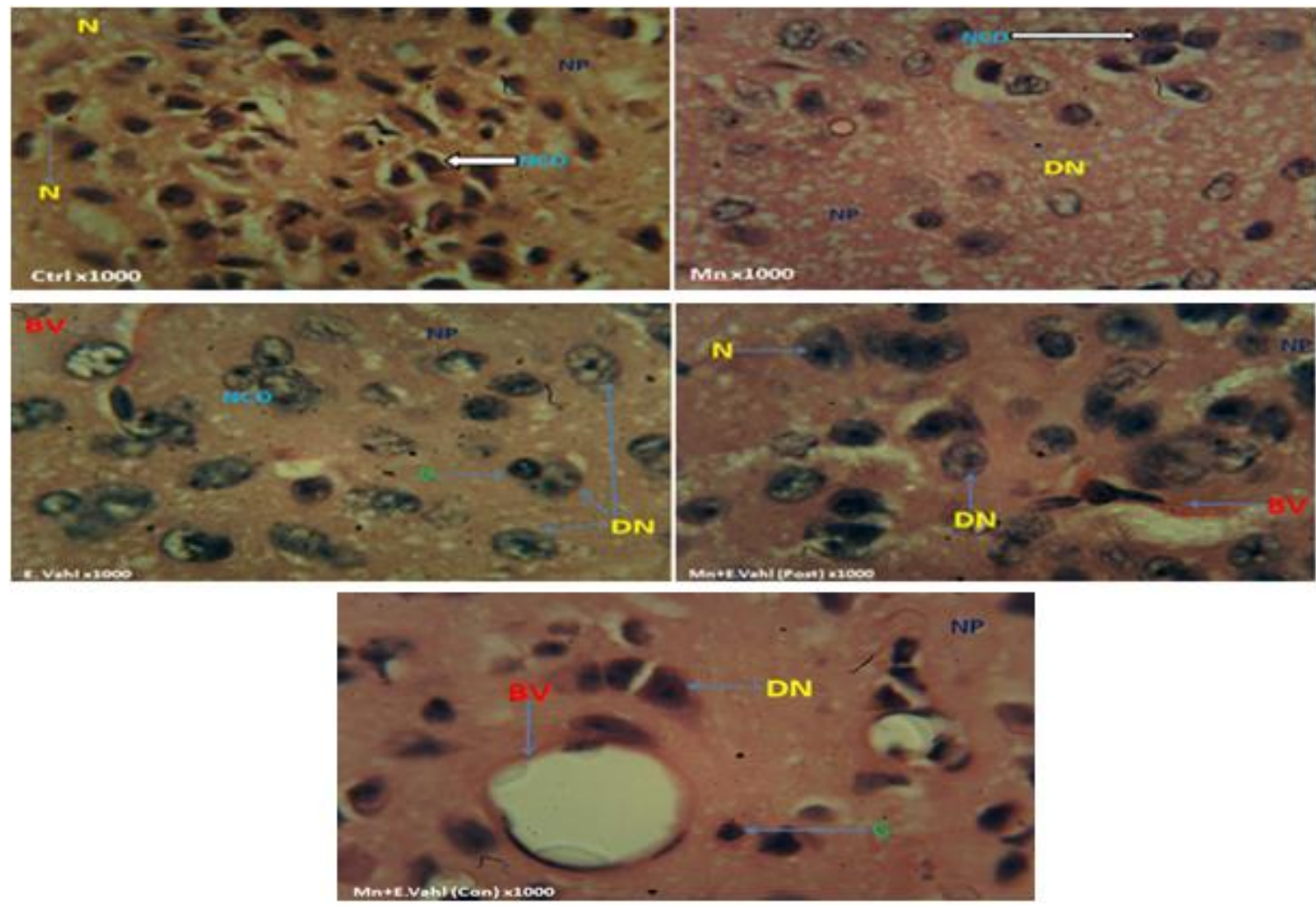

Figure 5: Showing the merged photomicrograph of the substantia nigra (SNc). NCD indicates the Neuronal cell distribution; BV indicates blood vessel and N indicate neurons and NP indicates the neurophil. H\&E. Mg. x1000

Table 1: Table showing phytochemical analysis of FEV leaves

\begin{tabular}{|c|c|c|c|c|}
\hline \multirow[t]{2}{*}{ Compounds } & \multicolumn{2}{|c|}{ Methanolic Extract } & \multicolumn{2}{|c|}{ Aqueous Extract } \\
\hline & & $\begin{array}{c}\text { Quantitative } \\
\text { (Mg/g) }\end{array}$ & Qualitative & $\begin{array}{r}\text { Quantitative } \\
(\mathrm{Mg} / \mathrm{g})\end{array}$ \\
\hline Phenols & + & 0.2880 & + & 0.2480 \\
\hline Tannin & + & 0.4435 & + & 0.4548 \\
\hline Alkaloids & ++ & 16.8010 & + & 15.9680 \\
\hline Saponin & ++ & 34.4990 & + & 34.4890 \\
\hline Flavonoid & + & 2.8060 & + & 3.1230 \\
\hline Glycosides & ++ & & - & \\
\hline Steroids & + & & & \\
\hline
\end{tabular}


Anatomy Journal of Africa. 2018. Vol 7 (2): 1206 - 1219
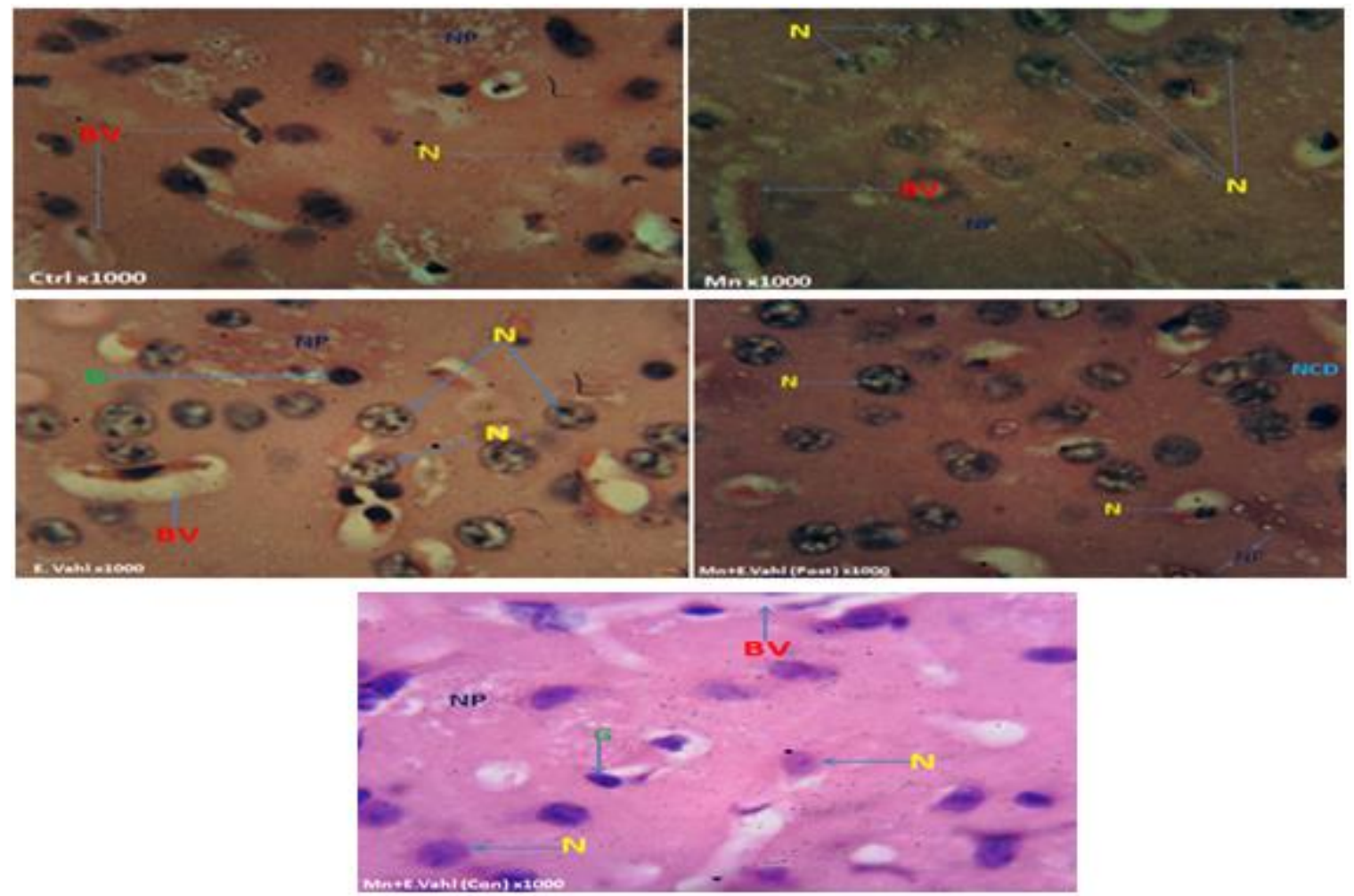

Figure 6: Showing the merged photomicrograph of the striatum (CPu). NCD indicates the Neuronal cell distribution, BV indicates blood vessel and $\mathrm{N}$ indicate neurons and NP indicates the neuropil. H\&E. Mg. x1000
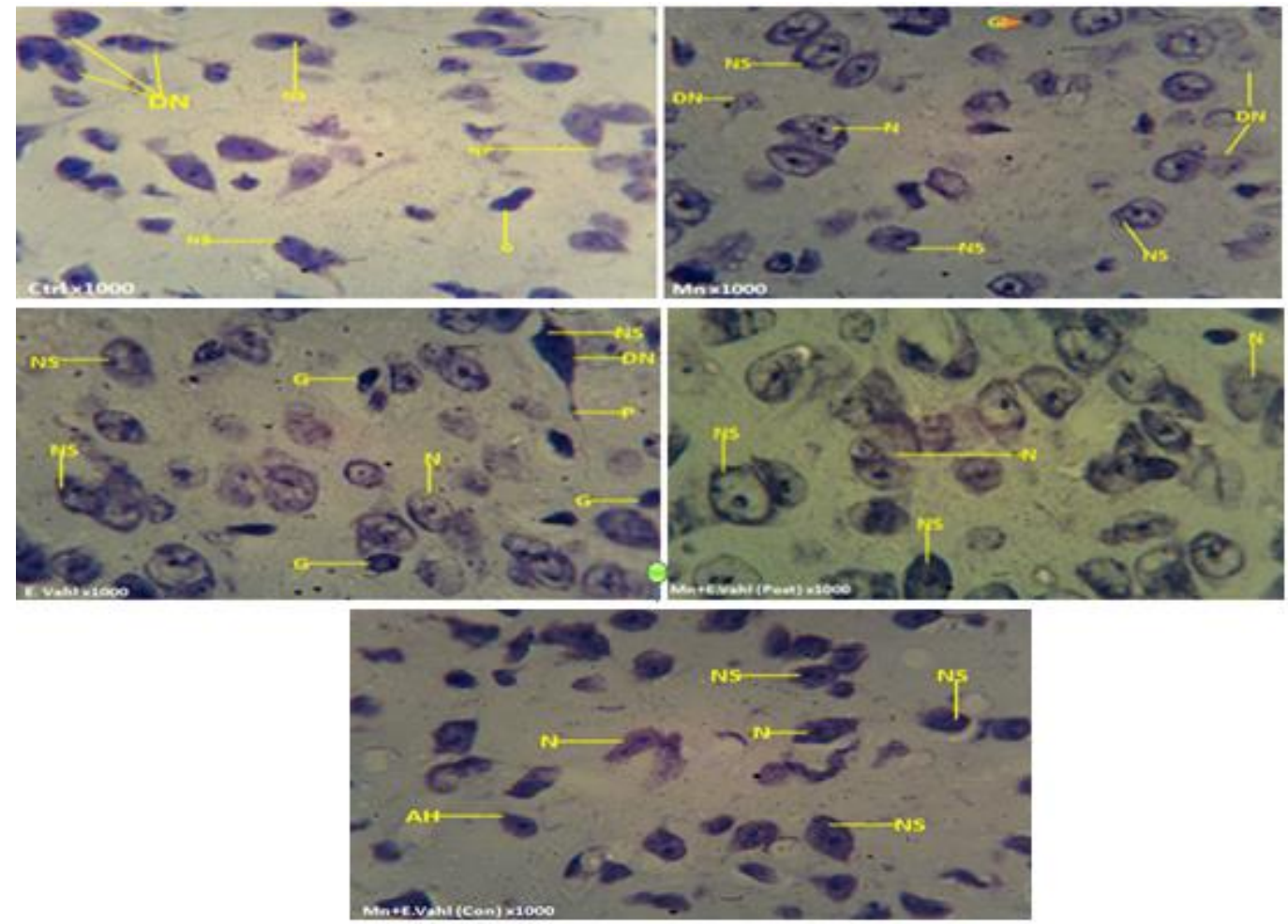

Figure 7: Showing the merged photomicrograph of the substantia nigra (SNc). NS indicates the Nissl substance; AH indicates Axon hillock; $\mathbf{N}$ indicate neurons and $\mathbf{G}$ indicates the Glial cell. CFV. Mg. x1000 

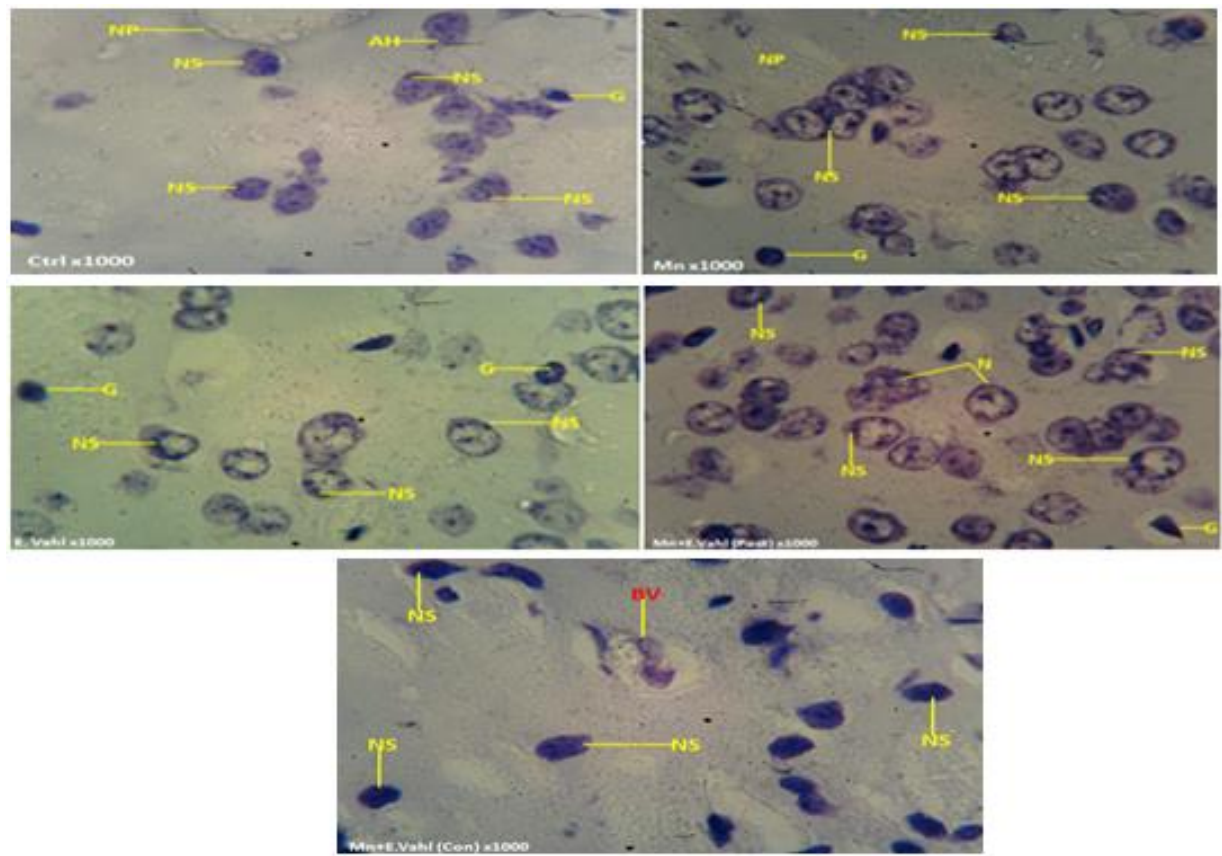

Figure 8: Showing the merged photomicrograph of the Striatum (CPu). NS indicates the Nissl substance; AH indicates Axon hillock; BV indicate blood vessel; $\mathbf{N}$ indicate neurons and $\mathbf{G}$ indicates the Glial cell. CFV. Mg. x1000
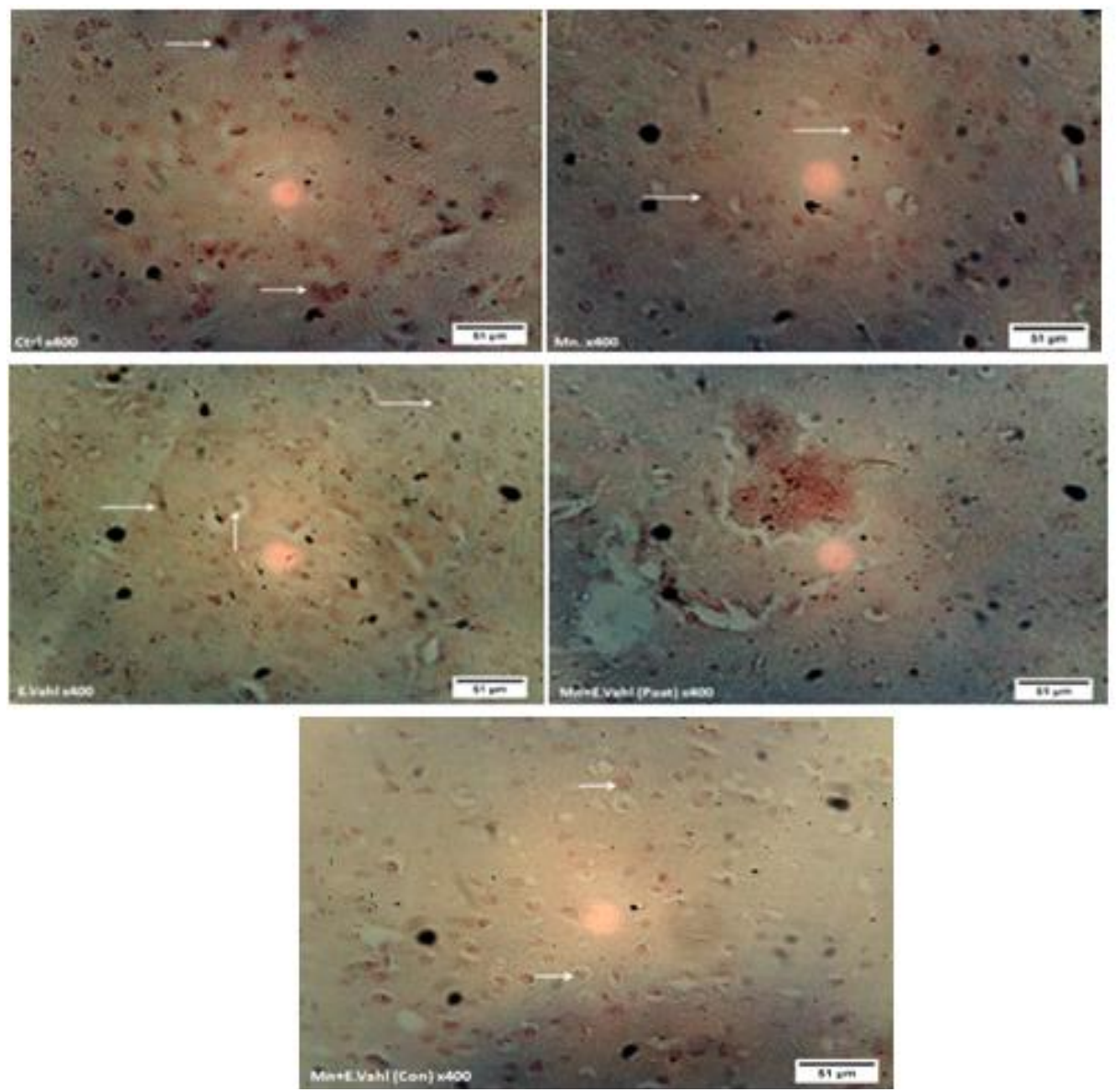

Figure 9: Showing the merged photomicrograph of the Substantia nigra (SNc) immunostained for TH. White arrow shows Tyrosine hydroxylase cells. Mg. x400 
Anatomy Journal of Africa. 2018. Vol 7 (2): 1206 - 1219
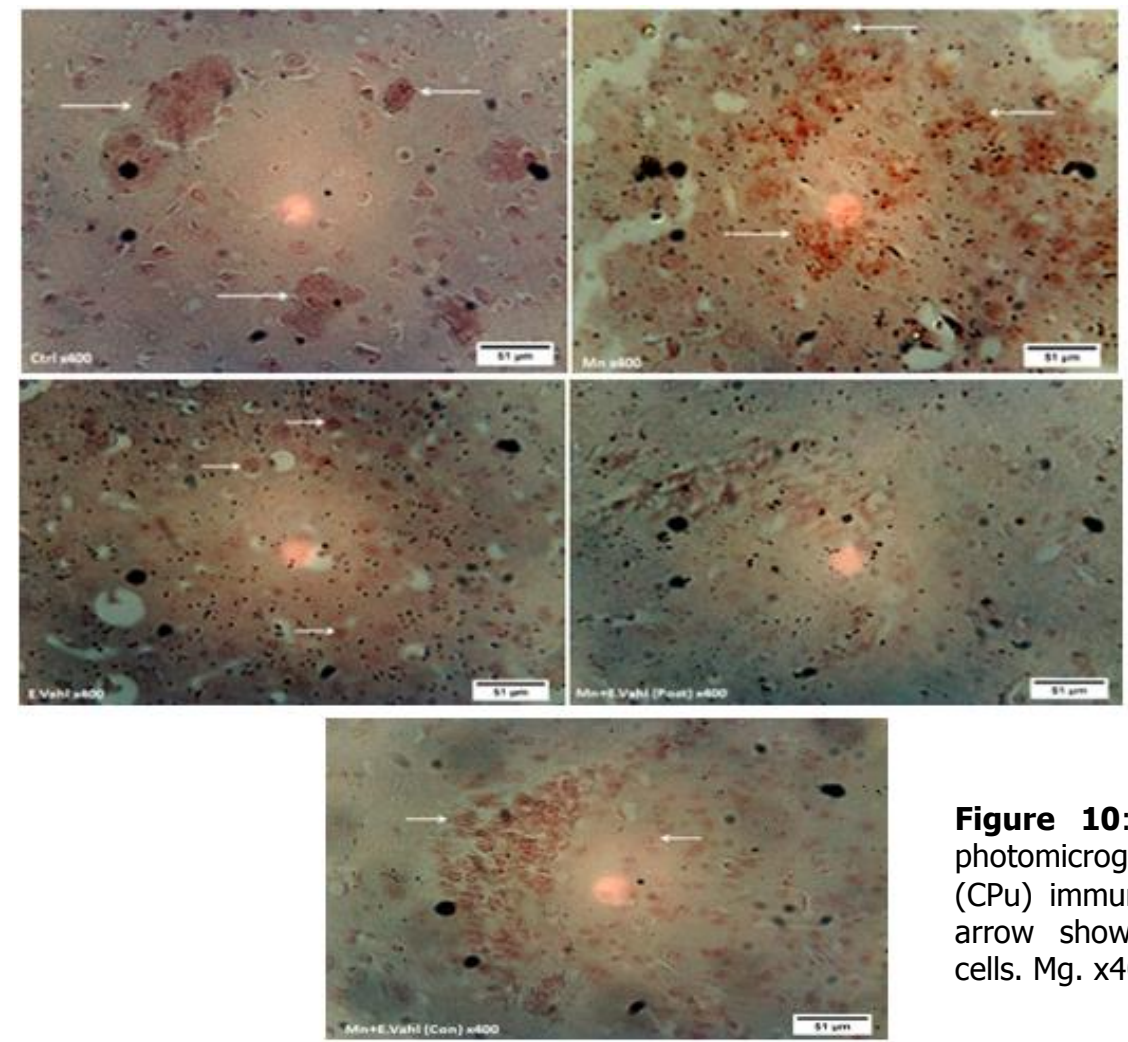

Figure 10: Showing the merged photomicrograph of the Striatum (CPu) immunostained for $\mathrm{TH}$. White arrow shows Tyrosine hydroxylase cells. Mg. $\mathrm{x} 400$

\section{GFAP Immunoreactivity}
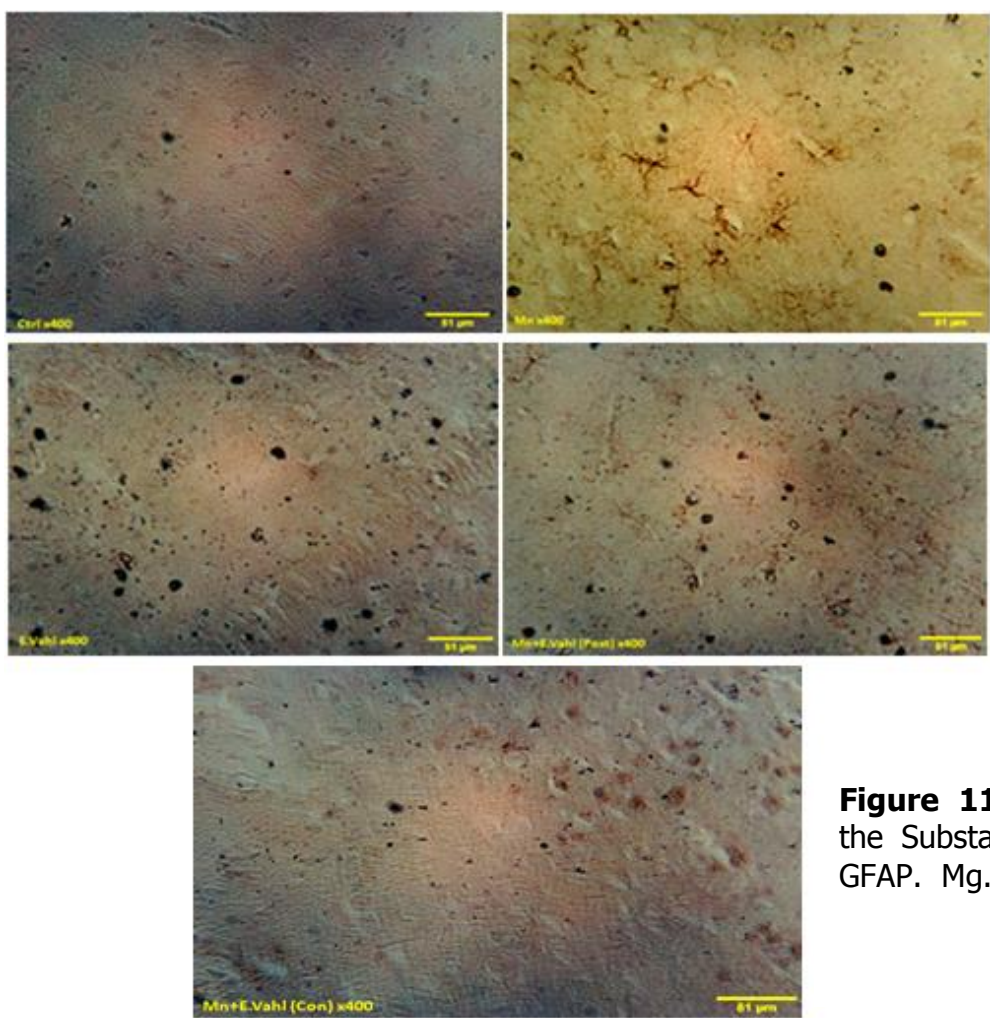

Figure 11: Showing the photomicrograph of the Substantia nigra (SNc) immunostained for GFAP. Mg. $x 400$ 
Anatomy Journal of Africa. 2018. Vol 7 (2): 1206 - 1219
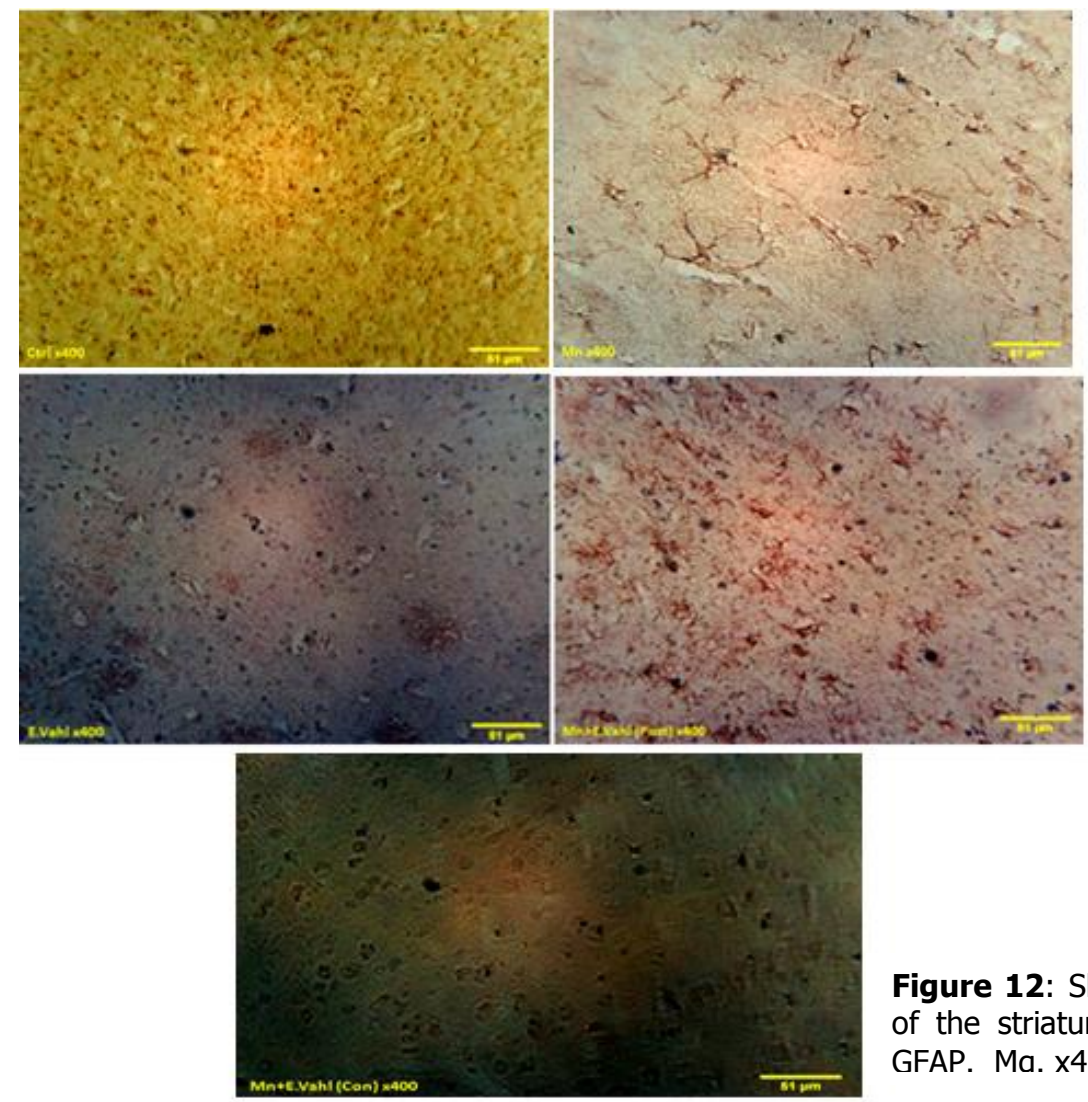

Figure 12: Showing the photomicrograph of the striatum (CPu) immunostained for GFAP. Ma. $x 400$

\section{CD11b/c Expression}
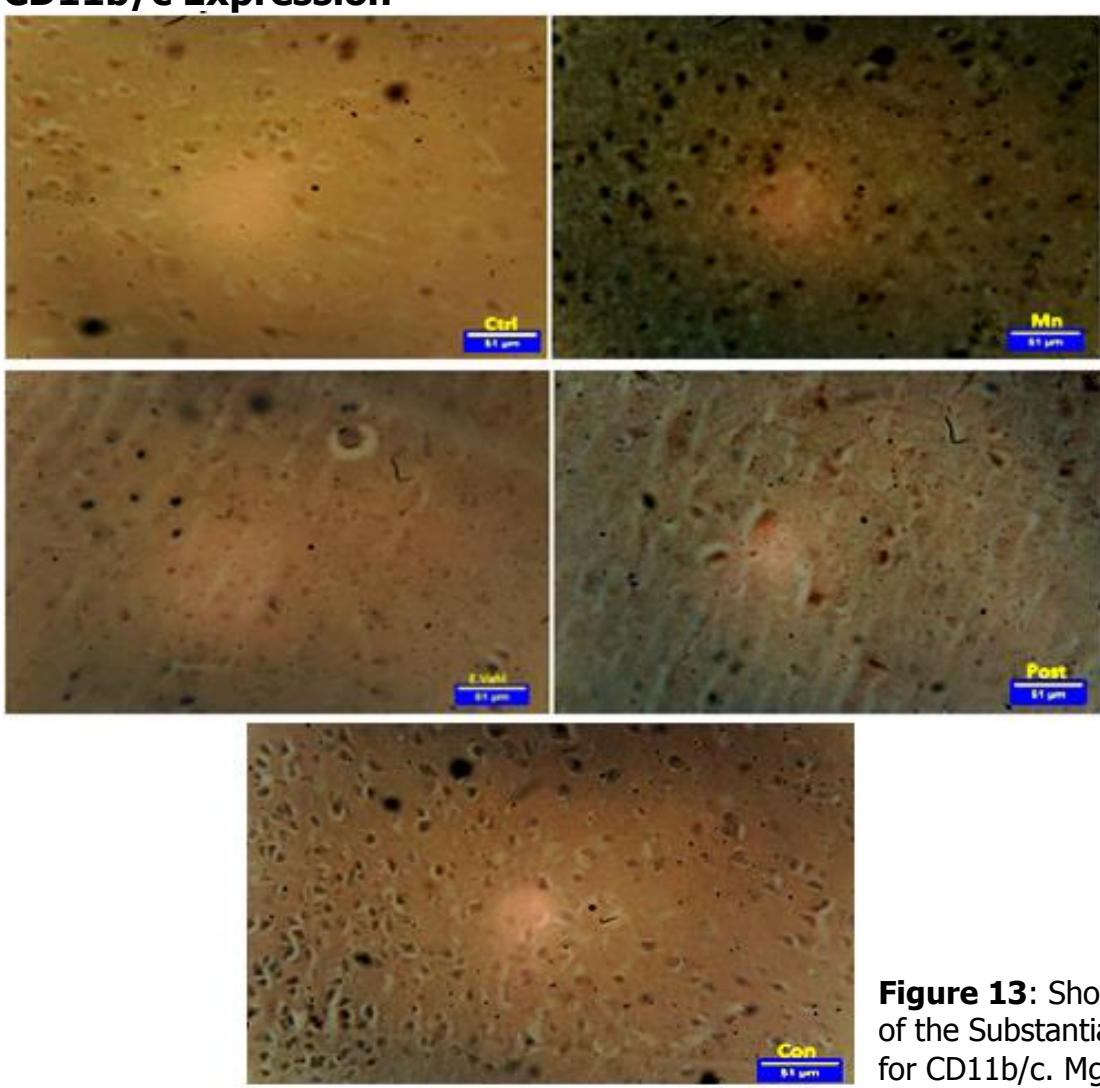

Figure 13: Showing the photomicrograph of the Substantia nigra (SNc) immunostained for CD11b/c. Mg. x400 

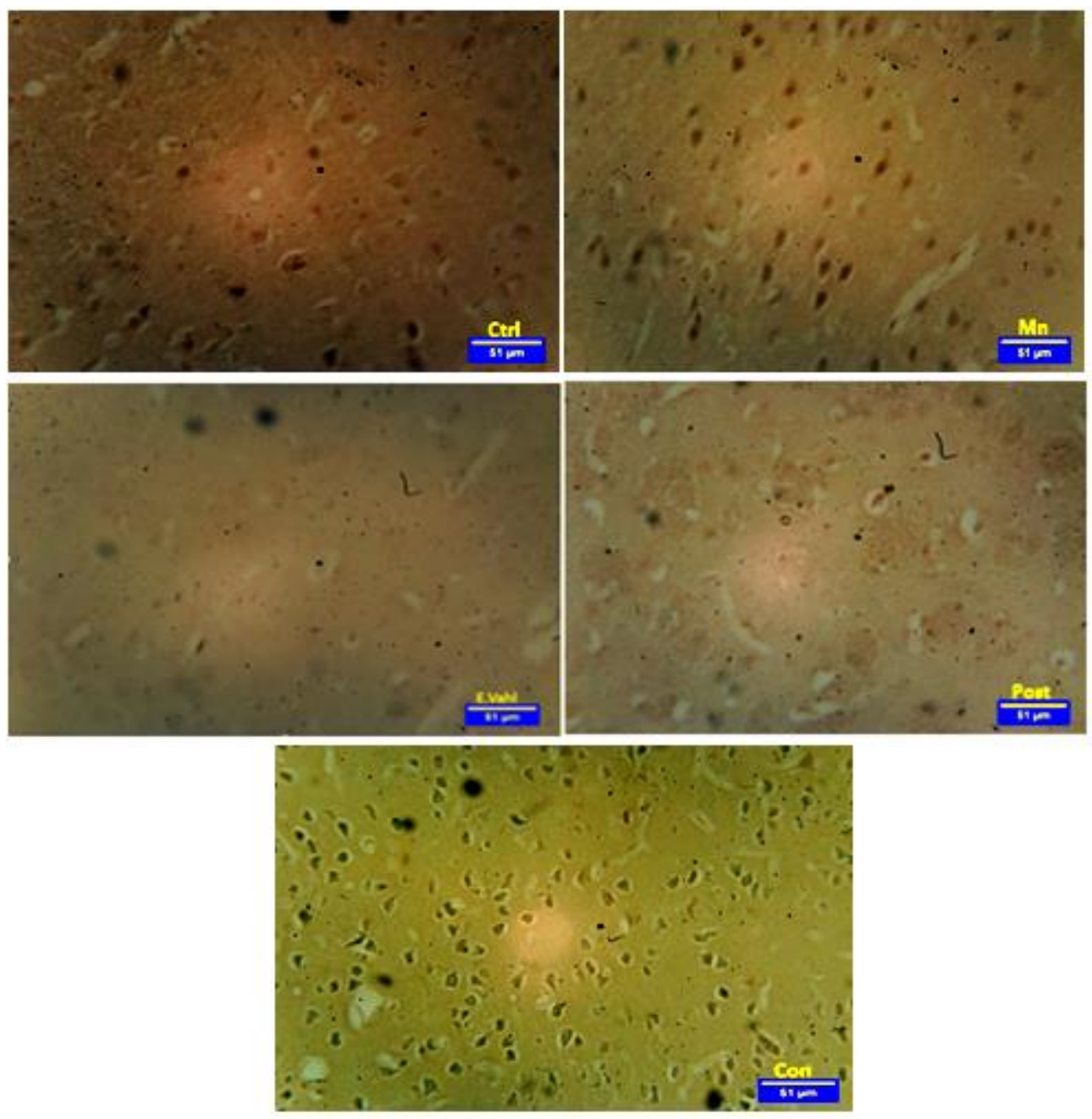

Figure 14: Showing the photomicrograph of the Striatum (CPu) immunostained for CD11b/c. Mg. $x 400$

\section{DISCUSSION}

Exposure of the brain to excessive amounts of manganese results in neurotoxicity which may lead to manganism (Fang et al., 2008). Dopaminergic neurons is a special type of neurons that can be linked to $\mathrm{Mn}$-induced motor deficit, because dopamine-rich regions, such as Striatum, substantia nigra and globus pallidus are affected in manganese toxicity (Hirata et al., 2008). The present study supports the reports above because of the neurobehavioral syndrome observed in the Balb/c mice which include motor deficit. The rotarod and Parallel bar test is commonly used in the assessment of motor coordination to characterize disease models (Carter et al., 1999), to determine the effects of pharmacological practices (Cartmell et al., 1991) and to determine phenotype strain or genetic profiles (Ingram et al., 1981; Serradj and Jamon, 2007). It has been reported that excessive exposure to manganese resulted in a poor motor coordination (Lao et al., 2017). However, in this study, rotarod and Parallel bar demonstrated a good motor coordination following ameliorative role of Ficus exasperate Vahl.

To ascertain the adverse neurological effects being observed in humans occupationally exposed to manganese (Roels et al., 1992), higher concentration of manganese was seen in manganism induced mice. However, FEV is very active in modulating the concentration of plasma manganese level. 
Hematoxylin and eosin staining technique was used to demonstrate general histoarchitecture of striatum and substantial nigra in this study. To demonstrate changes in neuronal nissl substances, Crysl fast violet stain was employed. In this study, FEV demonstrated an ameliorative role on the disrupted histoarchitecture of substantia nigra and striatum of manganese-exposed mice. Destruction of the Nissl bodies as a result of neurotoxicity incurred by the excessive accumulation of manganese is referred to as chromatolysis which is very critical in motor disorders pathogeneses like Parkinson's disease and amyolateral sclerosis (Kovacs, 2017). It is possible that this change in nissl substance distribution can reduce the size of the monosynaptic excitatory postsynaptic potentials (Sasaki et al., 1996). These functional changes to the motor neurons could result in the elimination of excitatory inputs thus producing motor function impairment as seen in the present study. On the other hand, FEV displayed ameliorative capacity, normal distribution of nissl substances and intact neurohistoarchitecture.

Dopamine is an important neurotransmitter in the brain, playing a modulatory role in the coordination of movement and cognition (Seth and Chandra, 1984; Tran et al., 2002). Dopaminergic cells loss evident in the substantia nigra and striatum of the manganese-exposed mice as seen in this study corroborates with the findings of Kim et al. 2017. Inflammatory responses in the central nervous system are elicited by non-neuronal glial cells, chiefly astrocyte and microglia, whose activities underlie several neurodegenerative disease pathogenesis (Fang et al., 2008; Touil et al., 2018). In this current investigation, excessive manganese exposure induced astrogliosis and microglia activation is an early sign of neuronal death, as evidenced in a similar study by Salvi et al, 2017.

A variety of plants serves as a repository of health and cure amongst many peoples. Most of these plants are accessible and inexpensive to the rural users. One of such plant with numerous biological activities is Ficus exasperate Vahl. Hence, in the present study, it is been evaluated for its role against motor function impairment and neurotoxicity occasioned by manganese intake. Currently, this is the only report on such which could serve as a reference point in the management of neurobehavioural motor deficit problem with the extract of FEV. Treatments with Methanolic extract of FEV improved motor function. Manganese plays crucial roles in different physiological processes, being a constituent of multiple enzymes and an activator of other enzymes (Sbodio et al., 2018). A manganese activated enzyme called manganese superoxide dismutase (MnSOD) is a principal antioxidant enzyme in the mitochondria, which catalyse the conversion of superoxide radicals in the mitochondria to hydrogen peroxide which can be reduce to water $\left(\mathrm{H}_{2} \mathrm{O}\right)$ by other antioxidants (Leach and Harris, 1997). It can be thus, postulated that the cellular restorative and regenerative potential of FEV in the present study is due to the upregulation of manganese superoxide dismutase (MnSOD) activity. With a deteriorated motor function after manganese exposure, treatment with FEV improved motor function possibly via the activity of up-regulated manganese superoxide dismutase (MnSOD) which could have prevented oxidative stress and apoptosis. This cellular repair ability of FEV initiated integration of the pre and post synaptic connection.

In conclusion, taken together, my findings demonstrate improved motor and coordinating activities in groups treated with FEV when compared with the control and manganese chloride $\left(\mathrm{MnCl}_{2}\right)$ groups. The results of the $\mathrm{H} \& \mathrm{E}$ stain revealed presence of degenerated neurons and pyknotic nuclei in the manganese chloride $\left(\mathrm{MnCl}_{2}\right)$ exposed group which was later improved as a result of the intervention of FEV extract. Integrity of the Nissl substances were preserved in the group treated with FEV as shown with Cresyl fast violet stain.

Immunohistochemical studies revealed a wellmarked expression of astrocytes and microglia which become more active during the process of neurodegeneration in all the groups that received manganese chloride. Therefore, from the present study it can be deduced that manganese accumulation in the brain can lead to astrocyte and microglia activation which might cause induced manganism. However, inflammations actively contribute to neuronal damage and death, but the 
intervention of FEV extract showed a remarkable improvement.

In conclusion, this study has shown that FEV leaf

extract has an ameliorative effect on some of the motor deficits caused by manganese chloride in the substantia nigra and striatum of male adult mice.

Conflict of Interest: The authors declare no conflict of interest.

Acknowledgements: The authors gratefully acknowledge the help of Mrs Peters, Chemistry Department of Afe Babalola University for invaluable assistance in preparation of the extract used. We also acknowledge the help of: Ishola Azeez of the Department of Anatomy, Afe Babalola University, Ado Ekiti, Nigeria, Olusola Saka of Anatomy Department, Obafemi Awolowo University, Ile-Ife, Osun State, Nigeria.

\section{REFERENCES}

1. Adebayo EA, Ishola OR, Taiwo OS, Majolagbe ON, Adekeye BT. 2009. Evaluations of the methanolic extract of Ficus exas-perata stem, bark, leaf and root for phytochemical analysis and antimicrobial activities. Afr. J. Plant Sci. 3 (12): 283-287.

2. Andersen M, Dorman D, Clewell H, Taylor M, Nong A. 2010. Multi-dose-route, multispecies pharmacokinetic models for manganese and their use in risk assessment. J. Toxicol. Environ. Health A.73: $217-234$.

3. Anderson J, Fordahl S, Cooney P, Weaver T, Colyer C, Erikson K. 2008. Manganese exposure alters extracellular GABA, GABA receptor and transporter protein and mRNA levels in the developing rat brain. Neurotoxicology. 29(6):1044-1053.

4. Andersen M, Gearhart J. Clewell H. 1999. Pharmacokinetic data needs to support risk assessments for inhaled and ingested manganese. Neurotoxicology, 20(2-3), 161-171.

5. Aschner M, Erikson K, Dorman D. 2005. Manganese dosimetry, Species differences and implications for neurotoxicity. CRC Crit. Rev. Toxicol.35:1-32.

6. Aschner M, Erikson K, Hernández E, Tjalkens R. 2009. Manganese and its role in Parkinson's disease: From transport to neuropathology. Neuromol. Med. 11:252-266.

7. Aschner M, Guilarte T, Schneider J, Zheng W. 2007. Manganese: Recent advances in understanding its transport and neurotoxicity. Toxicol. Appl. Pharmacol.221: 131-147.

8. Bennett, R. N., Mellon, F. A., Foidl, N., Pratt, J. H., Dupont, M. S., Perkins, L., \& Kroon, P. A. 2003. Profiling glucosinolates and phenolics in vegetative and reproductive tissues of the multi-purpose trees Moringa oleifera L. (Horseradish tree) and Moringa stenopetala L. Journal of agricultural and food chemistry, 51(12), 3546-3553.

9. Carter R, Lione L, Humby T, Mangiarini L, Mahal A, Bates G. 1999. Characterization of progressive motor deficits in mice transgenic for the human Huntington's disease mutation. J. Neurosci. 19, 32483257.

10. Cartmell S, Gelgor L, Mitchell D. 1991. A revised rotarod procedure for measuring the effect of antinociceptive drugs on motor function in the rat. J. Pharmacol. Methods. 26, 149-159.

11. Devbhuti D, Gupta JK, Devbhuti P, Bose A. 2009. Phytochemical and acute toxicity study on Tinospora tomentosa Miers. Acta. Pol. Pharm. 66: 89-92.

12. Dobson A, Erikson K, Aschner M. 2004. Manganese neurotoxicity. Ann. N. Y. Acad. Sci.1012:115-128.

13. Erikson K, Syversen T, Aschner J, Aschner M. 2005. Interactions between excessive manganese exposures and dietary iron-deficiency in neurodegeneration. Environ. Toxicol.Pharmacol. 19:415-421.

14. Erikson K, Thompson K, Aschner J, Aschner M. 2007. Manganese neurotoxicity: a focus on the neonate. Pharmacol Ther. 113(2):369-377.

15. Eriksson H, Lenngren S, Heilbronn E. 1987.Effect of long-term administration of manganese on biogenic amine levels in discrete striatal regions of rat brain. Arch. Toxicol. 59:426-431. 
16. Firenzuoli F, Gori L. 2007. Herbal medicine today: Clinical and research issues. Evidence Based Complement. Altern. Med. 4(1):37-40.

17. Fang Zhao, Tongjian Cai, Mingchao Liu, Gang Zheng, Wenjing Luo and Jingyuan Chen. 2008. Manganese induces dopaminergic neurodegeneration via microglial activation in a rat model of manganism. Toxicological sciences, 107(1), 156-164.

18. Frau L, Simola N, Plumitallo A, Morelli M. 2013. Microglial and astroglial activation by 3, 4methylenedioxymethamphetamine (MDMA) in mice depends on $S(+)$ enantiomer and is associated with an increase in body temperature and motility. J. Neurochem. 124:69-78.

19. Hassan S, Ladan M, Dogondaji R, Umar R, Bilbis L, Massan L, Ebbo A, Matazu I . 2007. Phytochemical and toxicological studies of aqueous leaves extracts of Erythrophleum africanum. Kak. J. Biol. Sci.10:3815-3821.

20. Hirata Y., Suzuno H., Tsuruta T., Oh-Hashi K., Kiuchi K. 2008. The role of dopamine transporter in selective toxicity of manganese and rotenone. Toxicology. 244, 249-256.

21. Ingram D, London E, Reynolds M, Waller S, Goodrick C. 1981. Differential effects of age on motor performance in two mouse strains. Neurobiol. Aging 2, 221-227.

22. Järup L , Persson B, Elinder C. 1995. Decreased glomerular filtration rate in cadmium exposed solderers. Occup Environ Med; 52: 818-22

23. Jarup, L. 2003. Hazards of heavy metal contamination. British Medical Bulletin, 68:167-182.

24. Jungmin NAMa., Kisok KIM. 2008. Abnormal motor function and the expression of striatal dopamine d2 receptors in manganese-treated mice.

Biol.Pharm. Bull. 31(10) 1894-1897.

25. Kornblith, E. S., Casey, S. L., Lobdell, D. T., Colledge, M. A., \& Bowler, R. M. 2017. Environmental exposure to manganese in air: Tremor, motor and cognitive symptom profiles. Neurotoxicology. 64: 152-158.

26. Kovacs, G. G. 2017. Cellular reactions of the central nervous system. In Handbook of clinical neurology (Vol. 145, pp. 13-23): Elsevier.

27. Kim, D.-S., Jin, H., Anantharam, V., Gordon, R., Kanthasamy, A., \& Kanthasamy, A. G. 2017. p73 gene in dopaminergic neurons is highly susceptible to manganese neurotoxicity. Neurotoxicology, 59, 231-239.

28. Kwakye, G. F., Paoliello, M., Mukhopadhyay, S., Bowman, A. B., Aschner, M. 2015. Manganese-induced Parkinsonism and Parkinson's disease: shared and distinguishable features. International journal of environmental research and public health, 12(7):7519-7540.

29. Lao, Y., Dion, L.A., Gilbert, G., Bouchard, M.F., Rocha, G., Wang, Y., Leporé, N. and Saint-Amour, D., 2017. Mapping the basal ganglia alterations in children chronically exposed to manganese. Scientific reports, 7, p.41804.

30. Leach, R. M., Jr., and E. D. Harris 1997. Manganese. In: B. L. O'Dell and R. A. Sunde Handbook of Nutritionally Essential Mineral Elements. p 335-356. Marcel Dekker Inc., New York.

(eds.)

31. Liu, B., Wang, M., \& Wang, X. 2018. Phytochemical analysis and antibacterial activity of methanolic extract of Bergenia purpurascens against common respiratory infection causing bacterial species in vitro and in neonatal rats. Microbial pathogenesis, 117, 315-319.

32. Mee-Young L, Chang-Seob S, In-Shik S, Young-Bum K, Jung-Hoon K, Hyeun-Kyoo S 2013. Evaluation of oral subchronic toxicity of soshiho-tang water extract: The traditional herbal formula in rats. Evidence-Based Complement. Altern. Med 2:1-9.

33. Oloruntoba, A. A., Chizoba, A., Adediran, F. A., Mayowa, A., Saheed, S., Phillimon, S., \& Kehinde, A. A. 2018. Evaluation of the Effects of Gutenbergia nigritana Leaves Extract on Cerebellum of Adult Mice and Its Implication on Manganese Toxicity. Pharmacy and pharmaceutical sciences. 3: 55-68.

34. Parent A, Carpenter MB 1996. "Ch. 1". Carpenter's Human Neuroanatomy. Williams \& Wilkins. ISBN 978-0-683-06752-1.

35. Peneder TM, Scholze P, Berger ML, Reither H, Heinze G, Bertl J, Bauer J, Richfield EK, Hornykiewicz O, Pifl C. 2011. Chronic exposure to manganese decreases striatal dopamine turnover in human a;phasynuclein transgenic mice. Neuroscience. 180:280-92. 
36. Perona MT, Waters S, Hall FS, Sora I, Lesch KP, Murphy DL, Caron M, Uhl GR. 2008. Animal models of depression in dopamine, serotonin, and norepinephrine transporter knockout mice: prominent effects of dopamine transporter deletions. Behav Pharmacol. 19(5-6):566-574.

37. Roels H, Ghyselen, P, Buchet J , Ceulemans E, Lauwerys, R. 1992. Assessment of the permissible exposure level to manganese in workers exposed to manganese dioxide dust. Br. J. Ind. Med.49, 25-34.

38. Salvi, V., Sozio, F., Sozzani, S., \& Del Prete, A. 2017. Role of Atypical Chemokine Receptors in Microglial Activation and Polarization. Frontiers in aging neuroscience, 9.

39. Sasaki M, Kitazawa S, Ohki Y, Hongo T. 1996. Convergence of skin reflex and corticospinal effects in segmental and propriospinal pathways to forelimb motoneurones in the cat. Experimental Brain Research. 107(3):422-34.

40. Sax N. 1984. Dangerous Properties of Industrial Materials. 6th ed. New York, NY: Van Nostrand Reinhold, . pg. 1729.

41. Sbodio, J. I., Snyder, S. H., \& Paul, B. D. 2018. Redox Mechanisms in Neurodegeneration: From Disease Outcomes to Therapeutic Opportunities. Antioxidants and Redox Signaling, (ja).

42. Seo, Y. A., Elkhader, J. A., \& Wessling-Resnick, M. 2016. Distribution of manganese and other biometals in flatiron mice. Biometals, 29(1), 147-155.

43. Serradj N., Jamon M. 2007. Age-related changes in the motricity of the inbred mice strains 129/sv and C57BL/6j. Behav. Brain Res. 177. 80-89.

44. Seth $P$, Chandra S. 1984. Neurotransmitters and neurotransmitter receptors in developing and adult rats during manganese poisoning. Neurotoxicology.5: 67-76.

45. Tijjani M, Bello I, Aluyu A, Olurishe T, Maidawa S, Habila J, Balogun E. 2009. Phytochemical and antibacterial Studies of Root Extract of Cochlospermum tinctorium A. Rich (Cochlospermaceae). Res. J. Med. Plants. 3: 16-22.

46. Touil, H., Kobert, A., Lebeurrier, N., Rieger, A., Saikali, P., Lambert, C., \& Antel, J. P. $2018 . \quad$ Human central nervous system astrocytes support survival and activation of $B$ cells: implications for MS pathogenesis. Journal of neuroinflammation, 15(1), 114.

47. Tran T. T., Chowanadisai W., Crinella F. M., Chicz-DeMet A, Lonnerdal B. 2002. Effect of high dietary manganese intake of neonatal rats on tissue mineral accumulation, striatal dopamine levels, and neurodevelopmental status. Neurotoxicology 23, 635- 643.

48. U.S. EPA. 1994. Guidelines for Developmental Toxicity Risk Assessment. U.S. Environmental Protection Agency. Federal Register 56:63798-63826.

49. Vidal L, Alfonso M, Campos F, Faro LRF, Cervantes RC, Duran R. 2005. Effects of manganese on extracellular levels of dopamine in rat striatum: an analysis in vivo by brain microdialysis. Neurochemical Research; 30:1147-115.

50. Woode E, Poku RA, Abotsi WK. 2011. Anxiolytic-like effects of a leaf extract of Ficus exasperata Vahl (Moraceae) in Mice. West Afr J Pharm. 22:75-81.

51. Yamada M, Ohno S, Okayasu I, Okeda R, Hatakeyama S, Watanabe H, Ushio K, Tsukagoshi H. 1986. Chronic manganese poisoning: A neuropathological study with determination of manganese distribution in the brain. Acta Neuropathol.70:273-278. 